\title{
POTPOURRI TESTICULAR TUMOUR- A RARE COMBINATION OF TESTICULAR SEMINOMATOUS MIXED GERM CELL TUMOUR WITH IMMATURE TERATOMA AND YOLK SAC TUMOUR IN A YOUNG ADULT MALE- A CASE REPORT
}

\author{
Probhas Kumar Sarkar', Partha Sarathi Mandal2, Kumar Dheeraj 3 , Saurabh Das ${ }^{4}$, Arindam Das 5
}

1Professor, Department of General Surgery, IPGME \& $R$.

${ }^{2}$ Postgraduate Trainee, Department of General Surgery, IPGME \& $R$.

${ }^{3}$ Postgraduate Trainee, Department of General Surgery, IPGME \& $R$.

${ }^{4}$ Assistant Professor, Department of General Surgery, IPGME \& $R$.

${ }^{5}$ Postgraduate Trainee, Department of General Surgery, IPGME \& $R$.

HOW TO CITE THIS ARTICLE: Sarkar PK, Mandal PS, Dheeraj K, et al. Potpourri testicular tumour- A rare combination of testicular seminomatous mixed germ cell tumour with immature teratoma and yolk sac tumour in a young adult male - A case report. J. Evolution Med. Dent. Sci. 2017;6(67):4826-4828, DOI: 10.14260/Jemds/2017/1047

\section{PRESENTATION OF CASE \\ History of Present Illness \\ A 33-year-old young male was admitted under care of our surgical unit with painless swelling in right side of scrotum for 3 months. He had cough, breathlessness and chest pain but no haemoptysis for last one month. Also, he had intermittent fever and significant involuntary weight loss and anorexia for last one month. There was no history of syncope or palpitation.}

\section{Past History}

No significant past medical and surgical history and no history of previous hospital admission.

\section{Family History}

No history of same illness in family members.

\section{Examination}

\section{General Survey}

Patient was sick-looking and dyspnoeic. Pallor was moderate and body temperature was raised. He had no cyanosis, icterus, clubbing or dependent oedema. Cervical lymph nodes were not palpable.

\section{Local Examination}

No organomegaly or remarkable positive finding in upper abdomen.

On examination of scrotum, a variegated nontender right testicular swelling (measuring $13 \mathrm{~cm} \times 7.5 \mathrm{~cm}$ approx.) was felt and the swelling was extended through groin to the right lower abdomen. The scrotal skin was free from mass. Another hard mass, measuring about $14 \mathrm{~cm} \mathrm{\times} 8 \mathrm{~cm}$ was present in the inguinal pouch.

Financial or Other, Competing Interest: None.

Submission 13-07-2017, Peer Review 10-08-2017,

Acceptance 16-08-2017, Published 21-08-2017.

Corresponding Author:

Dr. Partha Sarathi Mandal,

Royal Arcade,

$4^{\text {th }}$ Floor,

Near Pragati Sangha Club,

P. O. Baruipur,

Kolkata-700144.

E-mail: hemendra_partha@yahoo.co.in

DOI: $10.14260 /$ jemds $/ 2017 / 1047$

\section{(c) (i) $९$}

\section{Investigations -}

1. Haemoglobin- $6.4 \mathrm{~g} \%$.

2. Serum Tumour Markers-
a) $\mathrm{LDH}-356 \mathrm{U} / \mathrm{L}(115-210 \mathrm{U} / \mathrm{L})$
b) AFP- $56.6 \mathrm{ng} / \mathrm{mL}(0.0-8.5 \mathrm{ng} / \mathrm{mL})$
c) Beta hCG- $2010 \mathrm{mIU} / \mathrm{mL}(<5 \mathrm{mIU} / \mathrm{mL})$

3. Chest X-ray PA view- Bilateral multiple cannon ball opacities in both lung fields suggestive of pulmonary metastasis.

4. USG Findings -

a) In scrotum- An enlarged right testis with heterogeneous echogenicity (i.e., combined solid and cystic components), measuring $13 \mathrm{~cm} \mathrm{x} 7 \mathrm{~cm} \mathrm{x}$ $4 \mathrm{~cm}$.

b) In right inguinal region- Lymph nodal mass of 14 $\mathrm{cm} \times 7 \mathrm{~cm} \times 5 \mathrm{~cm}$ was detected.

c) In right pelvis- Suspected lymph nodal mass of $5 \mathrm{~cm}$ diameter was detected.

\section{DIFFERENTIAL DIAGNOSIS}

a) Common Causes of Painless Testicular Swelling

A. Germ cell Tumour

1. Seminoma

2. Non-seminoma (Teratoma)

B. Mixed germ cell tumour

C. Yolk sac tumour

D. Sex cord stromal tumour (Sertoli-Leydig cell tumour)

E. Lymphoma.

b) Other Possibilities

Old haematocoele.

\section{CLINICAL DIAGNOSIS: -}

Surgical Procedure Performed

After stabilisation of the patient, we performed right-sided high inguinal orchidectomy with excision of right-sided inguinal lymph nodal mass with excision of lymph nodal mass from right-sided pelvis (iliohypogastric region adjacent to right side of bladder).

We sent the right orchidectomy specimen, right inguinal lymph nodal mass and excised pelvic mass for histopathological examination.

\section{PATHOLOGICAL DISCUSSION}

The testicular tumour showed mixed germ cell tumour showing a combination of seminoma, immature teratoma and yolk sac tumour with metastasis in right inguinal lymph node. 
Tunica albuginea - Free of lesion.

Resection of spermatic cord- involved.

Pelvic mass- Metastasis.

Few Photomicrographs of our Patient's Histopathological Report are given below-

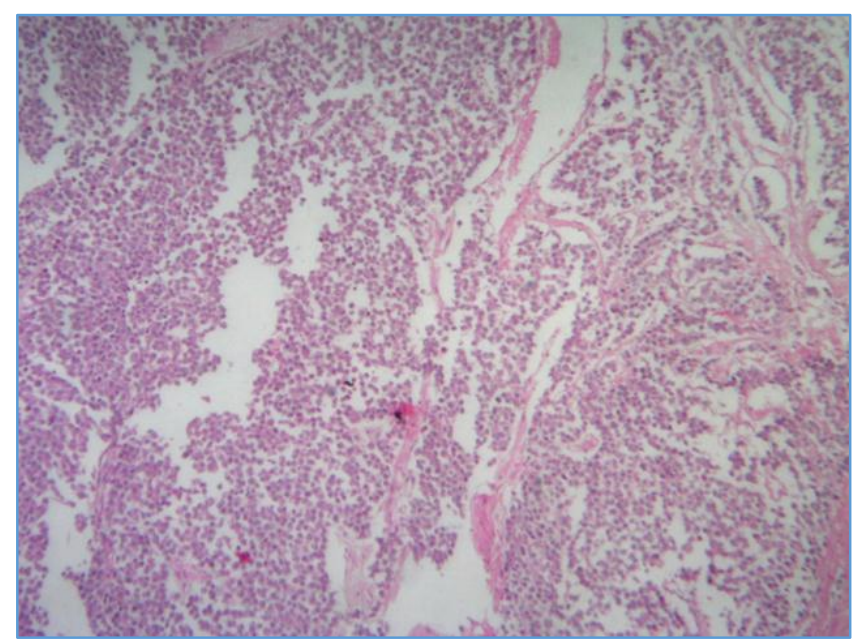

Figure 1a. Photomicrographs showing Seminomatous Component

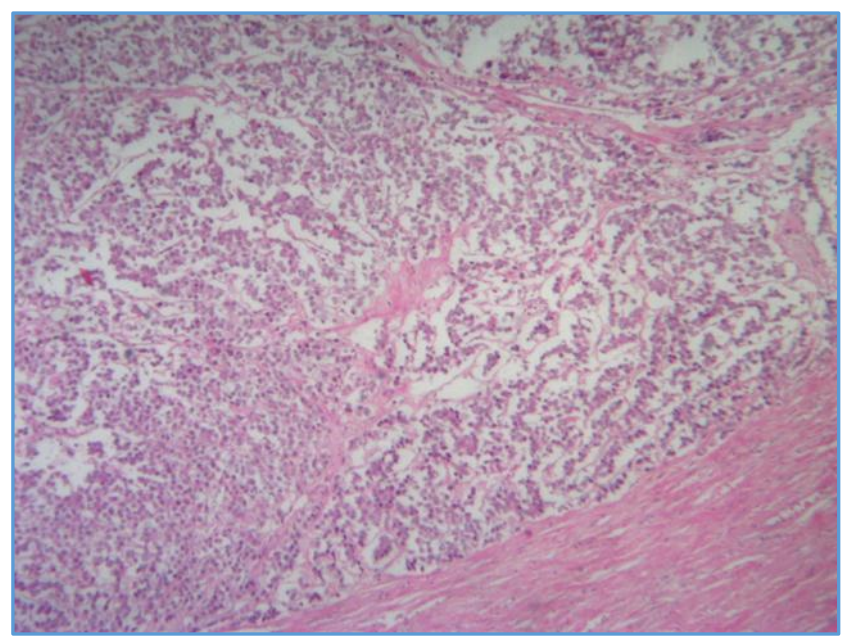

Figure 1b. Photomicrographs showing Seminomatous Component

Figure $1 \mathrm{a}$ and $1 \mathrm{~b}$ Photomicrographs show seminomatous component characterised by polyhedral cells with centrally placed nucleus and abundant pale cytoplasm separated by fibrovascular septae with lymphocyte infiltrate with adjacent yolk sac component having microcystic pattern.

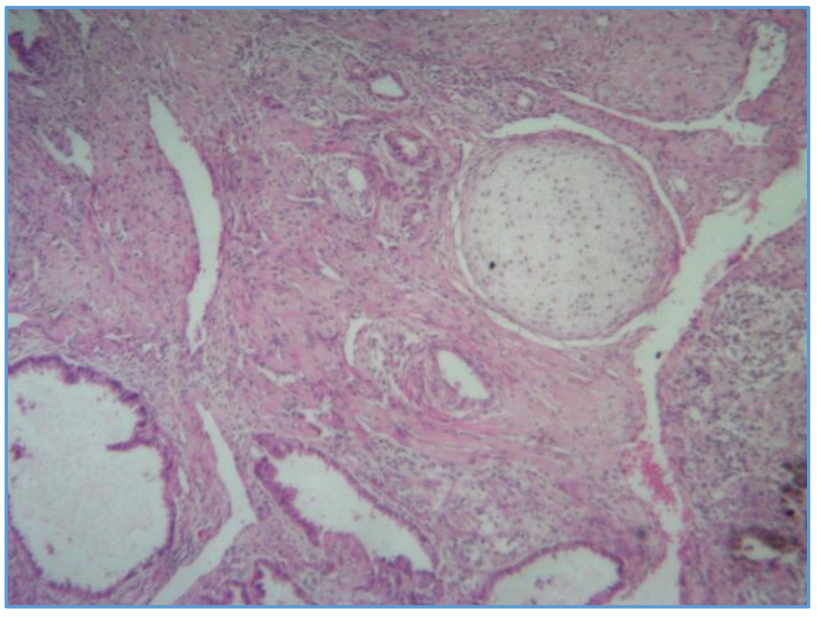

Figure 2. Photomicrograph showing Immature Cartilage, Glands and Acini, Abortive Tubules, Neutrophils, Fibrocollagenous Tissue consisting with Immature Teratoma.

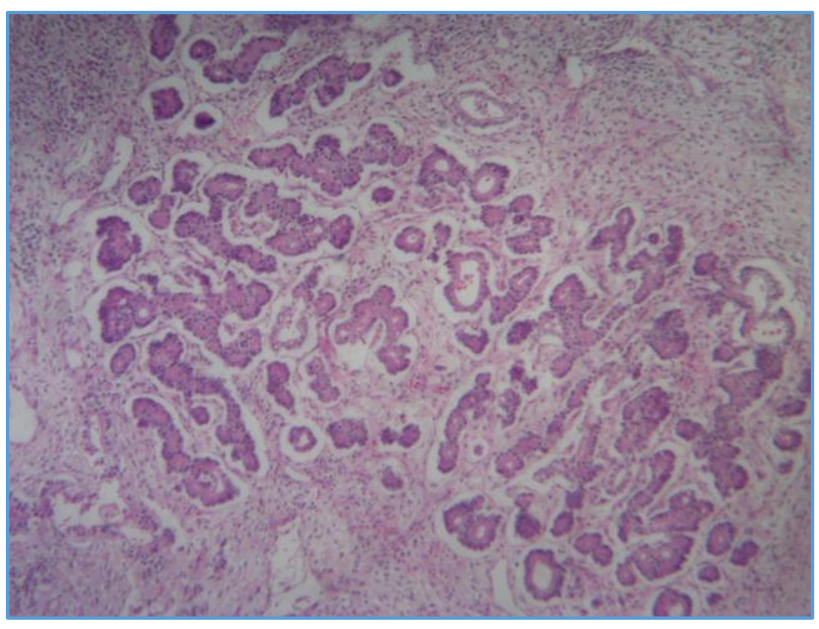

Figure 3. Photomicrograph showing Mixed Germ Cell Tumour of Testes

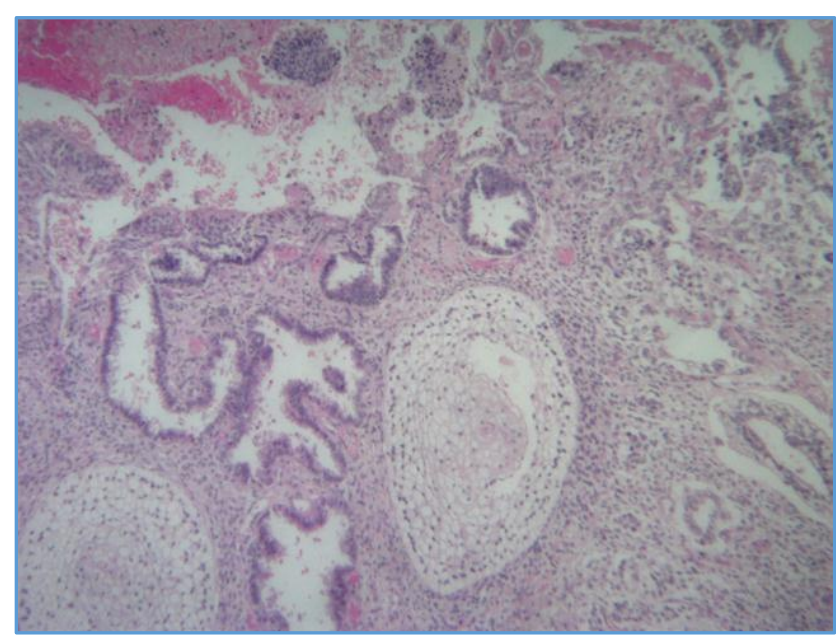

Figure 4. Photomicrograph showing features of immature Teratoma 


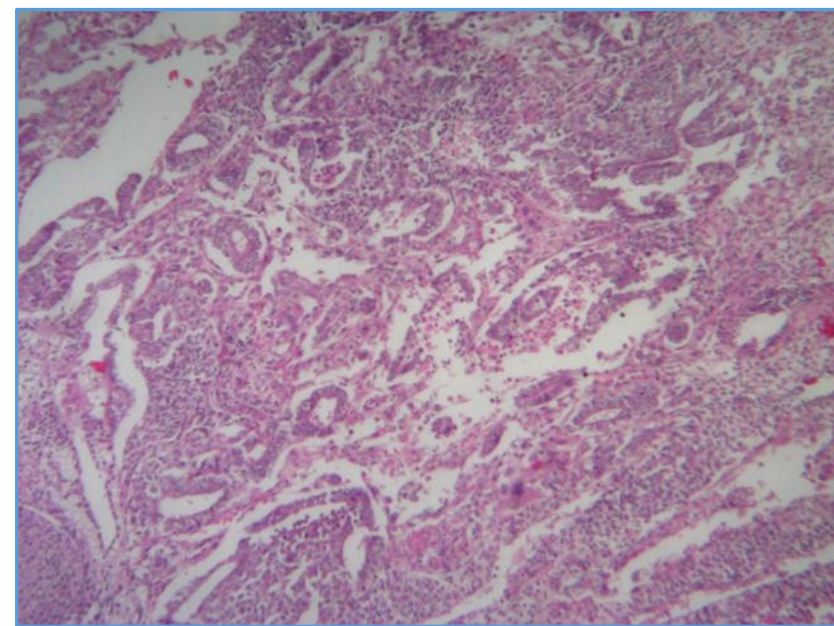

Figure 5. Photomicrograph showing Yolk Sac Tumour Exhibiting Microcystic, Papillary and Acinar Pattern, Presence of Hyaline Globules and Schiller-Duval Bodies

\section{DISCUSSION OF MANAGEMENT}

The patient was referred to Medical Oncology Department of our hospital for further evaluation and management plan after postoperative recovery.

In young males, about $99 \%$ of testicular neoplasms are malignant and used to be one of the common causes of mortality in them. Germ cell tumours (GCTs) comprise 95\% of malignant tumours arising in the testes and these are relatively uncommon and account for $1 \%$ of all male tumours. ${ }^{1}$

And testicular GCTs constitute the most common solid tumour in men between the ages of 20 and 34 years. ${ }^{2}$ For unknown reasons, the incidence of these tumours has been increasing in the past two decades. ${ }^{3}$

GCTs are classified as seminoma or nonseminoma. NSGCTs can be seen in pure and mixed forms. The mixed variety contains more than one germ cell component and comprises $32 \%-60 \%$ of all GCTs. But still the presence of seminomatous and non-seminomatous components in a GCT is rather unusual. ${ }^{4}$ Non-seminomatous tumours often include multiple cell types, including embryonal cell carcinoma, choriocarcinoma, yolk sac tumour and teratoma. Teratomas are considered to be either mature or immature depending on whether adult-type differential cell types or partial somatic differentiation, similar to that present in the foetus, is found.

The serum tumour markers - AFP, LDH and beta-hCG are critical in diagnosing GCTs, determining prognosis and assessing treatment outcome.

Gonadal GCTs possess diagnostically challenging issues for the pathologist and the correct diagnosis often has important therapeutic and prognostic significance.

Several studies have reported specific combinations of different GCT elements in mixed type of testicular GCTs. ${ }^{5}$ MOSTOFI found $>1$ histopathological patterns in approximately $60 \%$ of cases with the most frequent combination of embryonal carcinoma, yolk sac tumour and choriocarcinoma. In our patient, the histopathology showed the mixed type of testicular GCT - combination of seminoma, immature teratoma and yolk sac tumour. This combination was almost similar to that case as reported by Jena A. et al., where the mixed GCT of testes was the combination of seminoma, mature teratoma and yolk sac components. All these components in the orchidectomy specimen is a histopathological rarity, emphasizing the origin of these tumours as a process of multicentric neoplasia. ${ }^{6}$

Overall, non-seminomatous GCTs have poorer prognosis compared to seminomas. ${ }^{7}$ Majority of patients with NSGCTs present with advanced disease and they metastasise both through lymphatic and haematogenous route. ${ }^{7}$ The prognosis of mixed germ cell tumours depend on presence of the type and proportion of different histological components. ${ }^{8}$ As our patient presented with testicular tumour of short duration history with local lymph nodal spread and distant pulmonary metastasis, we can conclude that this rare type of mixed GCT has more aggressive course. Although further studies regarding this are essential.

\section{FINAL DIAGNOSIS}

In our patient, histopathological examination revealed the unusual combination of seminoma and non-seminomatous components (which were immature teratoma and yolk sac tumour). Though mixed GCT is commonly encountered in testes, presence of all these components in the orchidectomy specimen is a histopathological curiosity, emphasising the origin of these tumours as a process of multicentric neoplasia.

Thus, the present case not only reflects the heterogeneity in the biology of GCTs of the testes but also highlights the aggressiveness of this tumour considering the short duration of history and presentation with both local and distant metastasis in our patient.

\section{REFERENCES}

[1] Siegel RL, Miller KD, Jemal A. Cancer statistics, 2016. CA Cancer Journal for Clinicians 2016;66(1):7-30.

[2] SEER Cancer Statistics Factsheets. Testis Cancer. National Cancer Institute. Bethesda, MD. 2016. http://seer.cancer.gov/statfacts/html 2016.

[3] Huyghe E, Matsuda T, Thonneau P. Increasing incidence of testicular cancer worldwide: a review. J Urol 2003;170(1):5-11.

http://www.ncbi.nlm.nih.gov/pubmed/12796635.

[4] Sarrió PS, Chirivella I, Fos SN. Coexistence of two germinal cell tumours, seminomatous and nonseminomatous, with an uncommon clinical presentation. Arch Esp Urol 2008;61(5):626-30.

[5] Cheville JC. Classification and pathology of testicular germ cell and sex cord-stromal tumors. Urol Clin North Am 1999;26(3):595-609.

[6] Sesterhenn IA, Davis CJ. Pathology of germ cell tumours of the testis. Cancer Control 2004;11(6):374-87.

[7] Stamatiou K, Papadopoulos P, Perlepes G, et al. Mixed germ cell tumour of the testicle with ravdomuosarcomatous component: a case report. Cases J 2009;2:9299.

[8] Kruslin B, Turcic M, Cupic H, et al. Importance of determination of various histologic components in testicular germ cell tumours. Lijec Vjesn 2003;125(910):242-5. 